\title{
ALICANTE Y EL COMERCIO DE LA NIEVE EN EL ÚLTIMO TERCIO DEL SIGLO XVIII *
}

\author{
Por José MALLOL FERRÁNDIZ
}

Universidad de Alicante

Escribir acerca del comercio de la nieve en una ciudad mediterránea como Alicante, podría resultar algo insólito. Pero debiera parecérnoslo algo menos al observar que en nuestras montañas y en sus entornos todavía existen restos arquitectónicos e incluso construcciones completas de lo que en su día fueron pozos de nieve.

Y es que una actividad como la derivada de la recogida de la nieve, cuyo estudio pretendemos abordar en estas páginas, tenía razón de ser en nuestra área geográfica. En primer lugar, porque en la Edad Moderna la «industria frigorífica no podía más que basarse en el uso de la nieve y el hielo naturales; por otra parte, el propio clima de la ciudad de Alicante estimulaba a su población a consumir este helado producto en sus diferentes preparaciones: bien fuera en la fabricación de sorbetes, en la formación de aguas y vinos fríos, o como remedio terapéutico, principalmente para cortar hemorragias o para mitigar los efectos de las fiebres tercianas; finalmente, había un factor que potenciaba a los dos anteriores, es decir, la proximidad del arco montañoso, que a escasos kilómetros de la capital de la Gobernación de Alicante se elevaba por encima de los 1.000 metros y en cuyas zonas de umbría se situaban los pozos o neveras.

De esta manera, la historia del consumo de la nieve que se había desarrollado en la antigüedad clásica y tuvo su continuidad en el mundo medieval, cuajó - sobre todo impulsado por una abundante literatura médica favorable- en la Edad Moderna, alcanzando altas cotas de popularidad, de tal forma que las autoridades municipales, y las alicantinas no constituyeron una excepción, debieron ocuparse de regular detenidamente su abasto de nieve, insistiendo en la obligación de tenerla "así para los pobres enfermos como para los demás vecinos que enfermarían si hubiera faltado este preciso abasto» ${ }^{(1)}$.

Así pues, las ciudades hispanas, y en especial las de las riberas del Mediterrá- 
neo, pronto incluyeron el abastecimiento de la nieve dentro del capítulo de sus bienes propios y arrendaron su explotación a particulares, que se agruparon bajo el sistema de compañías. Estos arrendamientos tenían lugar mediante contratos minuciosos que detallaban las obligaciones del abastecedor - fundamentalmente, evitar la falta de nieve en la ciudad - y de los regidores que velaban por asegurar el monopolio del primero ${ }^{(2)}$.

Todas estas características generales son válidas para la centuria ilustrada, pero es a partir de 1760 cuando se inicia la fase más interesante en lo que al estudio del comercio de la nieve en Alicante se refiere. Es también la época cubierta con los más variados asuntos y en la cual la documentación es especialmente abundante, sobre todo en los años que van de 1785 a 1790 .

La temática es diversa y, en esquema, éstas son las cuestiones principales que pueden entresacarse: los memoriales de los abastecedores renovando sus obligaciones o protestando por la falta de reconocimiento de sus derechos, ante intrusiones de quienes pretendían sustituirles en el abasto; las polémicas surgidas de los diferentes criterios interpretativos de los contratos formalizados entre la ciudad y el abastecedor - ya fuera en lo concerniente a la venta de aguas frías, a la llegada de buques de guerra o a la instalación de las neverías de los barrios periféricos-; las diligencias llevadas a cabo por la ciudad para comprar nieve y hielo, en años en que la escasez en los parajes habituales (las sierras de Alcoy-Ibi y la sierra de Aitana) ocasionaba la falta de nieve a la población alicantina; las obras de cubrimiento de bóveda del pozo de la sierra de Aitana, propiedad de la ciudad de Alicante; y la instalación del alumbrado público de la ciudad, sufragado con un impuesto sobre el consumo de nieve. A los primeros temas se dedican los párrafos subsiguientes.

Desde que en cabildo de 22 de enero de 1760 se arrendó el abasto de nieve por 12 años a Vicente Pina, comenzaron a presentarse una serie de escritos que, amparándose en que no se había cumplido una de las cláusulas del arrendamiento, hacían puja ofreciendo mejoras para que el abasto cambiase de manos. En cabildo de 9 de marzo de 1762 fue hecha pública la postura de Joseph Boronat, que solicitaba la concesión del abasto por 12 años, al no haber nevado lo suficiente como para que se cumpliera la cláusula primera de la puja presentada por Vicente Pina en 1760, esto es, la de abastecer a la ciudad durante 10 años, desde 1762 ,

«si en este tiempo nevase palmo y medio de nieve, en las Sierras del Caño, Rincón de Milán, Carrascal de Alcoy, donde están situados losPozos, y dando de tiempo seis días para recogerla (...)» ${ }^{(3)}$.

Una junta municipal de abogados dictaminó que el abasto continuaría en favor de Vicente Pina si éste justificaba que la condición se había cumplido. Un testimonio certificado por el escribano de Ibi demostró la calidad de la nevada que tuvo lugar entre los días 5 y 6 de marzo de 1762, lo cual bastó para que Pina quedara obligado por el resto de los años de su arrendamiento ${ }^{(4)}$.

En otra ocasión el monopolio de Vicente Pina -que actuaba como repre- 
sentante de la Compañía de Picó y herederos - se vio quebrado por la concesión del arrendamiento del abasto de nieve del pago de la Santa Faz -incluido en los contratos de la ciudad de Alicante- a Joseph Moltó. Sin embargo, la comunidad de religiosas del monasterio continuó fiel a Pina, que les había servido durante muchos años. Ante la persistencia de las monjas, Moltó pidió ser relevado del abasto de dicho pago, lo que le fue admitido en 22 de julio de $1744^{(5)}$.

Jaime Picó —abastecedor entre 1781 y 1786 - y Salvador Borje —entre 1786 y 1790 - se adelantaron a posibles pretensiones de otras personas que optaron por el abasto, ratificando su obligación en sendos memoriales en los que aseguraban que llevarían a cabo su arrendamiento, punto por punto, pese a que no se había verificado la condición de nevar de un modo satisfactorio; sus nuevas propuestas incluían, además, mejoras en los precios que el cabildo no pudo recha$\operatorname{zar}^{(6)}$.

La calidad de los productos que se ponían a la venta era siempre objeto de polémica por sus compradores. En nuestro caso, la nieve se destinaba, en general, a particulares y a vendedores de aguas frías. Ambas partes exigían que aquello que compraban se presentase en buenas condiciones. En cabildo de 17 de julio de 1772 se leyó un memorial expresando las quejas de varios individuos del común, ya que advertían en la nieve más piedra y mezcla de tierra que otros años, protestando también de que el agua no se vendía tan fresca como en estíos anteriores, a lo que replicaban los aguadores que se debía a la primera causa expuesta y al aumento del precio de la nieve (que había pasado de cuatro a cinco dineros por libra de 18 onzas), lo cual reducía su margen de beneficios. Las providencias de los regidores se encaminaron a la resolución del tema, proponiendo que se hiciera «escandallo a los vendedores públicos de Agua fría dejándoles el correspondiente beneficio, para que con esto puedan dar el agua tan fría como hasta aquí se ha acostumbrado $(. ..) \gg(7)$.

El incremento del importe satisfecho por la nieve era frecuente motivo para que los aguadores solicitasen la actuación de los capitulares, con el fin de no ver mermadas sus ganancias. Para subsanar estas irregularidades se proponían dos medios: de una parte, reducir el vaso que se había señalado como medida -a lo que no accedieron los ediles puesto que calculaban un producto de 14 dieros por garrafón favorable a los aguadores - ${ }^{(8)}$; de otra, pretendían cobrar más por cada vaso. El cabildo, amparándose en las cláusulas contractuales del abasto, rara vez accedía a tales pretensiones en primera instancia. En la mayoría de las ocasiones mandaba realizar un experimento para comprobar la cantidad de nieve necesaria para enfriar suficientemente el agua de un garrafón, graduando así la «capacidad y precio a que deben venderse los vasos de agua, proporcionando la utilidad, aunque módica, a los Aguadores» ${ }^{(9)}$.

Al llegar la estación veraniega, el abastecedor tenía la obligación de colocar dos neverías - además de la principal, situada en la Plaza del Mar - en los arrabales de San Francisco y San Antón. La ubicación de las mismas constituyó una fuente de controversias entre los vecinos del arrabal, la ciudad y el abastecedor, 
sobre todo cuando la población se encontraba padeciendo una epidemia de fiebres tercianas. El plano de la ciudad setecentista determinaba la problemática situación de la nevería. En el arrabal de San Antón solía colocarse entre dos puertas - las de la Huerta y de la Reina-; al cerrarse durante la noche la puerta de la Reina quedaba cortada la comunicación con dicho arrabal, desabasteciendo a sus vecinos. En estas circunstancias, el cabildo alicantino proveyó en 1768 y 1779 que el abastecedor, Vicente Pina, emplazara la nevería dentro del barrio, y no entre las puertas, para mayor alivio de sus moradores ${ }^{(10)}$. Sin embargo, no siempre se encontraba el lugar idóneo para la instalación de la nevería. Cuando esto sucedía, era el cabildo el que ayudaba al abastecedor facilitándole un lugar como la Casa del Rafalí, propiedad de la ciudad y destinada a la venta de carnes ${ }^{(11)}$.

Finalmente, podía darse el caso de que estas neverías de los arrabales hubieran de permanecer abiertas más tiempo del estipulado. En cabildo de 29 de septiembre de 1777 así se mandó ejecutar, ordenando a Vicente Pina que mantuviera dichos despachos de venta de nieve durante el tiempo que siguieran registrándose casos de tercianas, pero disponiendo, en beneficio del abastecedor, que se suprimieran una o dos onzas por libra de nieve que se vendiera en los arrabales, para reintegrarle en sus pérdidas ${ }^{(12)}$.

La presencia de navíos de guerra y por consiguiente de tropas embarcadas en los mismos, era frecuente ya que en sus travesías mediterráneas buscaban el amparo y la seguridad de un puerto de excelentes condiciones como el alicantino. Estas expediciones, sin embargo, causaban graves trastornos en el abasto de nieve, incrementando el consumo y llevando a cabo requisas de caballerías utilizadas en el transporte de la nieve. Era obligación del cabildo intervenir en este asunto $\mathrm{y}$, previo informe del abastecedor, se determinaba el número de mulos que debían ponerse a disposición del mismo para que no se interrumpiera el abasto de la población. Pese al celo del cabildo, sus disposiciones no eran siempre atendidas. A finales del mes de julio de 1775 , una escuadra real y sus embarcaciones de transporte arribaron, procedentes de Argel, a la bahía de Alicante. Vicente Pina, abastecedor durante esos años, comunicó a los regidores que necesitaba 16 mulos diarios para el desempeño de sus tareas. Los oficios pasados al gobernador y corregidor de la plaza y al corregidor de Xixona no surtieron el efecto esperado, y las caballerías no llegaron, por lo que el encargado del abasto se vio imposibilitado de proveer de nieve a los buques, haciendo constar su protesta, pues así era su deber, y de esa forma no incurriría en las penas previstas en su contrata ${ }^{(13)}$.

Las diligencias llevadas a cabo por la ciudad y el abastecedor para conseguir la nieve necesaria para la población en años de escasez, ocupan un lugar destacado en la documentación, en especial en lo referente al año de 1786. La etapa que abarca los arrendamientos de Jaime Picó (1781-1786) y de Salvador Borje (17861800 ) registra una particular conflictividad. En ocasiones no se trataba de la falta de nieve en Alicante, sino que otras poblaciones - como la ciudad de Cartagenaintentaban que los abastecedores alicantinos les suministraran algunas cantidades. Pero los muchos compromisos que éstos tenían -Alicante, Elche, Orihuela, etc. - hacían inviable la satisfacción de esta petición ${ }^{(14)}$. 
Con anterioridad a la búsqueda de nieve en otras localidades, el Ayuntamiento instruía las diligencias conducentes a la averiguación de la nieve existente en los pozos que estaban obligados al abasto. El sumario concluido en 17 de marzo de 1786 dio como resultado la noticia de que en el pozo del Carrascal de Alcoy había 300 cargas de nieve, 250 de las cuales habían sido recogidas en octubre de 1785 y las 50 restantes en el propio mes de marzo; el pozo de Aitana, propio de la ciudad, contenía 337 cargas y media de unas 14 arrobas cada una; y el pozo del Simarro de 17 a 18 palmos de nieve, pero toda vieja, es decir, de años anteriores (15). En diciembre de dicho año y enero de 1787 se volvieron a practicar diligencias en los citados pozos, resultando haber 105 cargas en el Simarro, 90 en el Casrrascal y quedando lleno el pozo y ventisquero de la sierra de Aitana ${ }^{(16)}$. El pago de estas indagaciones correspondía al abastecedor. Para las mismas, la ciudad solía enviar a uno de sus regidores acompañado de un portero municipal. En septiembre de 1793, Salvador Borje satisfizo 240 Rs. Vn. por el viaje a las sierra de Ibi del regidor Joseph Javaloyes y el portero Diego Andrés para disponer de la provisión de nieve que faltaba a la población ${ }^{(17)}$. Precisamente, en el mes de mayo de ese mismo año, las autoridades municipales de Ibi ordenaban a un sujeto apellidado Pina que rellenara o tapara

«el pozo de nieve que está junto al camino del Sargaret en evitación de posibles accidentes para los viandantes, y de no efectuarlo dentro del plazo de 30 días se efectuará dicho relleno de oficio con costas a su cargo»" ${ }^{(18)}$.

Los problemas del abastecimiento de nieve debido a la escasez de la misma comenzaron a solucionarse en los últimos días de 1786. Hasta esas fechas la ciudad de Alicante había dirigido, con diferente éxito, su punto de mira hacia varios lugares, además de los habituales, con el fin de proporcionar a la población el beneficio esperado. La sierra de Aitana, usual reserva de nieve de la ciudad, ofrecía junto al pozo y ventisquero propios de la misma, un abundante número de clots y pozos cuyos dueños proponían a la ciudad el libramiento de una serie de cargas que, en momentos de carestía, ésta solía aceptar, Joseph Lloret, vecino de Alcolecha, se obligó en mayo de 1786 a suministrar 50 cargas de nieve de 13 arrobas cada una al precio de 25 reales valencianos de a 12 cuartos el real. La venta sería a la puerta del pozo de Lloret, «siendo sólo de su obligación cavarla, arromanarla, y entregarla al sujeto que destine esta Ilte. Ciudad» ${ }^{(19)}$. En esta oportunidad, el precio convino a las autoridades. No fue así cuando un mes después Joseph Pla y su compañero, también vecinos de Alcolecha, of recieron 600 arrobas a dos pesetas y media la arroba, cuando las pretensiones de la ciudad eran de 4 reales por arroba ${ }^{(20)}$.

En el mes de agosto la insuficiencia de nieve era extremadamente grave y la ciudad intentó acopiar algunas arrobas en Agres y Villena. Los intentos en la primera villa fueron fructíferos, consiguiéndose una porción de 600 arrobas del pozo que Joseph Puig y Cubelles, vecino de Onteniente, poseía en la Sierra Mariola. El precio acordado fue de 10 Rs. Vn. por arroba ${ }^{(21)}$. El ofrecimiento de unos ve- 
cinos de Villena de 500 arrobas de hielo a 16 reales cada una, y luego rebajados a 15 fue desestimado por el cabildo ${ }^{(22)}$. Ante una nueva oferta al precio de 10 reales cada una de ellas, los regidores acordaron la realización de un experimento para ver a cuánto saldría una libra de nieve, una vez deducidas las mermas, el valor del hielo y el coste de la conducción. El precio de la libra debió resultar superior a los 18 dineros por cada 18 onzas, ya que el cabildo prefirió una oferta de 500 arrobas de nieve vieja que Bartolomé Rico aseguraba por el mismo importe ${ }^{(23)}$.

El expediente más completo perteneciente a dicho año de 1786, en el que Vicente Pina comisionado por la ciudad se hizo cargo del abasto - pues no se habían cumplido las condiciones de una nevada suficiente para obligar al abastecedor - es el relativo al hielo que fue traído desde Elda. El regidor alicantino Joseph Nicolás Alcaraz se ocupó del asunto al ser diputado por el cabildo. Durante los meses de marzo y abril los resultados no fueron los deseados. El precio máximo que había ofrecido la ciudad era "lo más hasta cuatro Pesos menudos a la Puerta del Pozo cada carga de 12 arrobas Peso de esta Ciudad (...)» (24). Los dueños de los pozos de Elda pedían, sin embargo, medio duro, precio al cual no estaba autorizada la admisión por parte de Alcaraz.

La cercanía del verano y el aumento del consumo hizo reflexionar a las autoridades alicantinas que prefirieron un coste elevado a la falta del producto, por lo que Joseph Alcaraz fue enviado de nuevo a Elda para averiguar el precio más ventajoso a que pudiera conseguirse el hielo. En 8 de junio se formalizó la escritura por la cual la ciudad compraba a Miguel Juan y Vidal y a Miguel Juan y Tormo, vecinos de esa villa, 5.000 arrobas de hielo, cada una de las cuales se consiguió al precio de 9 Rs. Vn. ${ }^{(25)}$. Al mes de haber empezado las extracciones de hielo, una carta de los interesados de Elda comunicaba que apenas quedaba hielo para ir sacando durante ocho días, y que, en vista de la escasez no podían más que ofrecer el resto de lo que se fuese extrayendo al elevado precio de 3 pesetas la arroba ${ }^{(26)}$. En realidad se trataba de una maniobra de engaño descubierta por los regidores Torregrosa y Tomás, que recriminaron a los propietarios de los pozos por haber faltado a la verdad, ya que sus cálculos confirmaban que apenas se había sacado una quinta parte de la capacidad de los pozos; por lo tanto, les instaba al cumplimiento de su obligación o que aseguraran un mínimo de cargas para evitar pérdidas ${ }^{(27)}$. La nueva obligación se hizo en la cantidad de 1.500 arrobas que habían de sacarse a un ritmo de 50 diarias. El valor de cada arroba se fijaba en 10 reales, debiéndose entregar un adelanto de 300 libras en el momento en que se iniciasen las extracciones ${ }^{(28)}$. Posteriormente, se aseguraron 300 arrobas más en el caso de que las 1.500 compradas en principio resultaran insuficientes para el consumo urbano de Alicante ${ }^{(29)}$.

El control que durante este tiempo ejerció el cabildo y la actividad de los regidores encargados del abasto de la nieve se ve reflejado en las numerosas referencias que se hallan en los libros correspondientes a dicho año conservados en el archivo alicantino. El número de arrobas del que se disponía diariamente era 
conocido por el edil comisionado y reflejado en las actas capitulares para prever posibles necesidades y que se tomaran las providencias oportunas para evitar la falta de nieve. La rigurosa estación veraniega así lo determinó, pues, aunque quedaban 1.700 arrobas en los depósitos de la ciudad -800 de ellas correspondientes al hielo de Elda, y 900 de parte del asentista Antonio Picó-, se acordó que el regidor Joseph Alcaraz tratara con los dueños del hielo eldense sobre la compra de 500 nuevas arrobas, o cualquier porción mayor que éstos pudieran ofrecerle ${ }^{(30)}$.

La relación entre la villa de Elda y la ciudad de Alicante en lo referente a la provisión de hielo finalizó cuando la Justicia de Elda decretó el cierre del pozo que surtía a la ciudad, causando un grave perjuicio a la población ${ }^{(31)}$, cuyos magistrados hubieron de realizar gestiones en otras partes para que el público no quedara desabastecido.

A partir de 1787 y como consecuencia de las nevadas que afianzaron el abasto, las dificultades ocasionadas por la escasez pasaron a un segundo plano y el sacrificio que los habitantes alicantinos habian hecho, pagando por la nieve y el hielo un precio bastante más elevado del habitual no fue en vano. La administración que la ciudad, por medio de Vicente Pina, había efectuado de los caudales del abasto, reportó unos beneficios de 404 libras y 11 dineros,

«(...) cuya cantidad, no habiéndose extraído de las Arcas ppcas. por vía de préstamo ni en otra manera, no procede reintegro ni encierro en ellas; y sí que se invierta en beneficio, y alivio del vecindario que la contribuyó con el aumento, y variedad de precios que según los apuros y necesidades del verano inmediato, y parte del otoño, fue preciso dar a la nieve en fuerza de providencias económicas tomadas por la ciudad a falta de abastecedor de dho. ramo; $(\ldots.){ }^{(32)}$

El principal destino de esta suma fue el de servir de aportación a la instalación del alumbrado público de Alicante. En los años inmediatamente siguientes, este aumento y el impuesto para la construcción de la bóveda del pozo de la Sierra Aitana, llenarán gran número de páginas de la documentación municipal. Independientemente de dichos temas, el abasto de nieve continuó con las pautas que se habían marcado desde los últimos años del siglo XVII y que se consolidaron de un modo pleno en la segunda mitad del XVIII.

De este modo, varias son las conclusiones que se desprenden de lo hasta aquí expuesto, a las que nosotros añadimos algunas otras a las que hemos llegado al finalizar nuestra Memoria de Licenciatura. En primer lugar se constata la importancia del abasto de nieve dentro del capítulo de los demás abastos urbanos, principalmente en localidades del Mediterráneo español. En otro nivel se sitúa la popularización del consumo de la nieve en Alicante, en contra de la opinión de quien la consideraba un artículo exclusivamente de lujo; esta tendencia a un elevado consumo se vio estimulada por el propio clima estival de la ciudad y por la proximidad del arco montañoso en el que se hallaban situados los pozos de nieve.

La atención que las autoridades municipales alicantinas prestaron al tema 
durante los siglos XVII y XVIII, procurando satisfacer una necesidad que su población demandaba, se acrecentó sobre todo a partir de 1760, coincidiendo con la reorganización de la política municipal llevada a cabo por los gobiernos ilustrados de Carlos III. Asimismo, la Hacienda Real también mostraba su interés en una actividad que le suponía sustanciosos ingresos, recaudados a través del Derecho Real de la Nieve, que en la segunda mitad del siglo XVIII vino a suponer una cantidad superior a los 30.000 reales de vellón anuales. Por su parte, también fueron significativas las inversiones surgidas del negocio de la nieve, que posibilitaron la financiación de obras ciudadanas, como las ya reseñadas acerca de la instalación del alumbrado público o la construcción de pozos de nieve para asegurar la continuidad del abasto.

Por último, reseñar que el comercio de la nieve y su organización ejercieron una influencia beneficiosa en numerosas gentes, al generar una fuerte dosis de empleo, que tenía en el verano su mayor cota de ocupación. Desde el personal empleado en la recogida de la nieve, pasando por los trabajadores en el interior de los pozos, los numerosos trajineros y arrieros, hasta los ocupados en la ciudad, como los vendedores de aguas frías o los propios encargados del corte de la nieve y venta al por menor, un sinfín de personas hicieron de la nieve un complemento a sus economías, cuando no se trató de su nropio medio de vida. 


\section{NOTAS}

* Este trabajo constituye el resumen de uno de los apartados de la Memoria de Licenciatura que, bajo la dirección del doctor Enrique Giménez López, fue defendida en la Facultad de Filosofía y Letras de la Universidad de Alicante, en octubre de 1987, con el título: «Comercio y renta de la nieve en Alicante en la Edad Moderna».

(1) Archivo Municipal de Alicante (en adelante A. M. A.) Cabildos. 1724, Arm. 9, Lib. 14, ff. 124-125, acta capitular de 26 de abril.

(2) El estudio de los aspectos contractuales del arrendamiento del abasto de la nieve fue objeto de tratamiento en otro de mis trabajos. Vid. «Alicante y el abasto de nieve en el siglo XVIII», Homenaje al Doctor Sebastián García Martínez, Valencia, 1987, 17 fols. mecanografiados (en prensa); asimismo, un estudio más detallado constituye una de las partes de nuestra Memoria de Licenciatura.

(3) A. M. A. Arrendamientos y fianzas. 1760-1761, Arm. 8, Lib. 44, ff. 16-17v.

(4) A. M. A. Arrendamientos y fianzas. 1762, Arm. 8, Lib. 48, ff. 15v-27v, Junta de Abastos de 20 de marzo.

(5) A. M. A. Cartas Escritas. 1771-1775, Arm. 12, Lib. 61, correspondencia de 22 de julio de 1774.

(6) A. M. A. Cabildos. 1785, Arm. 9, Lib. 80, ff. 321v-344v, acta capitular de 29 de octubre, y Arrendamientos y fianzas. 1787-1788, Arm. 8, Lib. 61, ff. 13-15, Junta de Abastos de 9 de febrero de 1787.

(7) A. M. A. Cabildos. 1772, Arm. 9, Lib. 67, ff. $21 \mathrm{v}-22$.

(8) A. M. A. Cabildos. 1774, Arm. 9, Lib. 69, ff. 247-248, acta capitular de 15 de julio.

(9) A. M. A. Cabildos. 1786, Arm. 9, Lib. 81, ff. 213v-214, acta capitular de 1 de septiembre.

(10) A. M. A. Cabildos. 1768, Arm. 9, Lib. 61, ff. 78-78v, acta capitular de 22 de abril, y Cabildos. 1779, Arm. 9, Lib. 74, f. 103, acta capitular de 15 de marzo.

(11) A. M. A. Cabildos. 1791, Arm. 9, Lib. 86, s.f., acta capitular de 20 de mayo.

(12) A. M. A. Cabildos. 1777, Arm. 9, Lib. 72, ff. 279-280.

(13) A. M. A. Cabidos. 1775, Arm. 9, Lib. 70, ff. 228v-231, actas capitulares de 28 de julio y 1 de agosto.

(14) A. M. A. Cartas Escritas. 1781-1783, Arm. 12, Lib. 64, ff. 43v-44v, correspondencia de 15 de marzo de 1781 .

(15) A. M. A. Cabildos. 1786, Arm. 9, Lib. 81, ff. 64-66.

(16) Ibíd. ff. $271 \mathrm{v}-273$, acta capitular de 20 de diciembre de 1786, y Cabildos. 1787, Arm. 9, Lib. 82, ff. 16-17v, acta capitular de 19 de enero.

(17) A. M. A. Cabildos. 1793, Arm. 9, Lib. 88, s.f., acta capitular de 20 de septiembre.

(18) Luis BARRACHINA VICEDO: Programa de Fiestas, Ibi, 1978.

(19) A. M. A. Arrendamientos y fianzas. 1785-1786, Arm. 8, Lib. 60, ff. 82v-84, Junta de Abastos de 8 de abril de 1786 .

(20) A. M. A. Cabildos. 1786, Arm. 9, Lib. 81, ff. 136 y 140-141, actas capitulares de 26 de mayo y 2 de junio. 
(21) A. M. A. Reales Privisiones y otros Papeles. 1786, Arm. 1, Lib. 65, ff. 212-219v.

(22) A. M. A. Cabildos. 1786, Arm. 9, Lib. 81, ff. 210-211, acta capitular de 27 de agosto.

(23) Ibid. ff. 221v-222v, acta capitular de 9 de septiembre de 1786.

(24) Ibíd. ff. 97v-98v, acta capitular de 10 de abril de 1786.

(25) A. M. A. Reales Provisiones y otros Papeles. 1786, Arm. 1, Lib. 65, ff. 204-206.

(26) A. M. A. Cabildos. 1786, Arm. 9, Lib. 81, f. 186.

(27) A. M. A. Cartas Escritas. 1784-1786, Arm. 12, Lib. 65, ff. 179-181v, correspondencia de 8 de julio de 1786 .

(28) A. M. A. Cabildos. 1786, Arm. 9, Lib. 81, ff. $187 \mathrm{v}-188 \mathrm{v}$, acta capitular de 11 de julio.

(29) A. M. A. Cartas Recibidas. 1786, Arm. 12, Lib. 65, ff. 107-108, correspondencia de 13 de julio.

(30) A. M. A. Cabildos. 1786, Arm. 9, Lib. 81, ff. 200-200v, acta capitular de 7 de agosto.

(31) Ibid. ff. 208-209v, acta capitular de 25 de agosto de 1786.

(32) Ibid. ff. $274 \mathrm{v}-275 \mathrm{v}$, acta capitular de 22 de diciembre de 1786. 